\title{
SISTEMA BRASILEIRO DE COMISSÕES PARLAMENTARES
}

\section{BRAZILIAN SYSTEM OF PARLIAMENTARY COMMITTEES}

João Pedro Paro*

Resumo: Investiga as Comissões Parlamentares do Congresso brasileiro sob um aspecto normativo-institucional, mas também empírico tendo em vista que há uma abordagem sobre a efetiva quantidade de comissões e de seus membros. A análise aborda, portanto, as comissões parlamentares brasileiras, sob aspectos relacionados ao tipo de comissões, seu funcionamento e características, mecanismos legislativos, tempo de duração, forma de recrutamento, número de membros, profissionalização, dando especial relevo para as Comissões Permanentes da Câmara dos Deputados. Verificou-se que o crescimento da quantidade de comissões ao longo do tempo, aliado a outros fatores, como o grau de institucionalização na Constituição de 1988 e a quantidade de Comissões presentes atualmente no processo legislativo do Congresso Nacional, revelam que o sistema de Comissões cumpre um papel importante no processo legislativo, tanto como espaço de deliberação, como aprimoramento técnico do trabalho legislativo.

Palavras-chaves: Comissão Parlamentar; Poder Legislativo; Instituições; Recrutamento.

Abstract: The main objective of this article is to investigate the Parliamentary Committees of the Brazilian Congress under a normative-institutional aspect, but also considering empirical approach to be an effective amount of commissions and their members. The analysis therefore addresses the Brazilian parliamentary committees, in aspects related to the type of commission, operation and features, legislative mechanisms, length, form of recruitment, membership, professional, with particular reference to the Standing Committees of the House of Representatives. It was found that the growth of the amount of commissions over time, combined with other factors such as the degree of institutionalization in the 1988 Constitution and the amount of commissions currently present in the legislative process of the National Congress, show that the system of commissions plays an important role in the legislative process, both as deliberation space such as technical improvement of legislative work.

\footnotetext{
* João Pedro Paro, Especialista em Ciência Política, Graduado em Direito pelo Centro Universitário das Faculdades Metropolitanas Unidas/FMU, Graduado em Ciências Sociais pela USP. É Pesquisador do Núcleo de Políticas Públicas da USP/NUPPs na área de Instituições e Advogado Tributarista. (joaopedro.paro@gmail.com)
} 
Keywords: Parliamentary Committee; Legislature; Institutions; Recruitment;

\section{Introdução}

O objetivo principal deste trabalho é investigar as Comissões Parlamentares do Congresso Brasileiro sob um aspecto normativo-institucional, mas também empírico tendo em vista que há uma abordagem sobre a efetiva quantidade de comissões e de seus membros.

Trata-se de um trabalho que levará em consideração a evolução histórica das comissões no processo legislativo no Brasil, até mesmo porque qualquer conceito (inclusive jurídico) possui uma história, que necessita ser retomada e reconstruída para que se possa rastrear a evolução da simples palavra para o conceito e assim apreender seu sentido.

Ademais, proceder-se-á numa análise dos tipos de comissões existentes no Legislativo brasileiro para que se tenha real consciência da variação das atribuições e encargos de cada tipo de comissão, bem como da efetiva amplitude do sistema de comissões que ora serve para investigar, ora para deliberar, ora para juntar senadores e deputados para a deliberação de determinado assunto, e assim por diante.

Assim, para melhor compreensão do sistema de comissões brasileiro, não deixaram de ser avaliadas as características de funcionamento das comissões, levando-se em consideração aspectos regimentais e constitucionais de sua composição, número de membros, bem como a quantidade de comissões existentes atualmente no Congresso Nacional e em cada Casa Legislativa, e até mesmo a variação do número de comissões ao longo de 25 (vinte e cinco anos) de democracia no Brasil.

Por fim, a forma de recrutamento para as comissões no Brasil é peculiarmente esclarecedora haja vista que colabora para a compreensão do processo legislativo e a sua divisão interna de trabalho.

Neste sentido, trata-se de uma análise das comissões parlamentares brasileiras, que aborda aspectos relacionados ao tipo de comissões, seu funcionamento e características, mecanismos legislativos, duração das comissões, forma de recrutamento, número de membros, profissionalização, além de dar especial relevo para as Comissões Permanentes da Câmara dos Deputados, a fim de se esboçar um trabalho eminentemente descritivo, porém problematizando os dados que serão ilustrados.

De toda forma, serve o presente como uma tentativa de introdução inicial do tema na agenda de pesquisa para futura discussão e compreensão mais ampla sobre o sistema brasileiro de comissões parlamentares. 


\section{Evolução histórica das comissões no processo legislativo no Brasil}

As comissões, como órgãos colegiados, ditos menores, têm sua formação respaldada na necessidade de divisão do estudo e análise das matérias concernentes aos mais diversos tipos de proposições levadas ao Poder Legislativo através das vozes da sociedade.

Nesse sentido, o objetivo das comissões é múltiplo, haja vista serem órgãos de estudo, análise e discussão das proposições, bem como instância legislativa onde se apresentam pareceres e são exercidas funções de controle e fiscalização dos planos e programas de governo.

O fato é que ao se esboçar uma digressão histórica sobre as Comissões Parlamentares de uma forma geral, a literatura menciona que os parlamentos começaram a se organizar em comissões para que fosse facilitado o estudo e análise das matérias no parlamento.

Bartthélemy (apud SILVA, 2007) entende que a instituição das comissões corresponde a um princípio instintivo, espontâneo e comumente admitido de método de organização dos trabalhos. Seria, portanto, impossível a uma assembleia no plenário, pesada e numerosa, a discussão de pormenores em suas minúcias dos projetos que exigem certas capacidades técnicocientíficas.

O costume vem dos tempos dos Comuns, na Inglaterra do século IV, onde o Committee necessitava que a deliberação dos discursos se desse longe dos ouvidos do rei e somente sob os auspícios dos "Membros de Confiança" (trustworthy members). A primeira Constituição a prever o sistema de comissões foi a da França em 25 de julho 1793.

No caso brasileiro, o surgimento das Comissões no Parlamento se deu com a Assembleia Constituinte em 1823, onde na primeira sessão preliminar foram criadas duas Comissões: i) a Comissão de Poderes, com cinco membros, incumbida de analisar a regularidade dos diplomas dos deputados eleitos e do processo eleitoral; ii) uma outra Comissão de Poderes, com três membros, que avaliava os diplomas da primeira Comissão de Poderes (CASSEB, 2008). Após as sessões preliminares, houve a abertura oficial na qual foi criada a Comissão Especial do Regimento, a Comissão de Constituição e a Comissão de Minas e Bosques, no dia cinco de maio de 1823.

Ao longo da Assembleia Constituinte, foram criadas muitas outras comissões parlamentares. Por essa razão, ganha especial relevo a Constituição Imperial de 1824, pois foi a primeira Carta Magna que menciona, no seu bojo, a figura das Comissões Parlamentares no art. $53^{1}$.

O período da Primeira República 1889-1930, por sua vez, não reservou grande espaço institucional para as Comissões Parlamentares. Assim, conforme Sandoval (2001), apesar de terem sido instituídas várias comissões no período de vigência da Constituição de 1891,

\footnotetext{
${ }^{1}$ Art. 53.O Poder Executivo exerce por qualquer dos Ministros de Estado a proposição, que lhe compete na formação das Leis; e só depois de examinada por uma Comissão da Câmara dos Deputados, aonde deve ter principio, poderá ser convertida em Projecto de Lei.
} 
nenhuma delas levou a termo sua tarefa, pois os parlamentares ainda não tinham plena consciência da função delas.

Ao contrário do que ocorreu na Constituição de 1891, a Carta Maior de 1934 privilegiou as Comissões Parlamentares, fazendo diversas referências a esses órgãos, inclusive no art. 26, prevendo como obrigação da Câmara e do seu Regimento Interno assegurar, quanto possível, a representação proporcional das correntes de opinião presentes. Verifica-se, neste norte, que já estava presente o germe do princípio plural e representativo que as comissões possuem até hoje. Casseb (2008), ao comentar o artigo 26 da carta de 1934, ressalta que a norma constitucional atrelou a representação proporcional às correntes de opinião e não aos partidos políticos.

Outro ponto de fundamental importância, lembrado por Nina (2005) é o da criação das Comissões Parlamentares de Inquérito, as CPI's, na Constituição de 1934, afirmando o poder institucional de investigação das comissões. Porém, no período de vigência dessa Carta Magna, houve seis CPI's propostas, embora apenas duas concluídas.

Tal situação favorece uma visão de avanço e fortalecimento das comissões, devido à criação do instituto que permitiu investigação e controle pelo Parlamento, mesmo que não tenha havido efetivo aproveitamento. Nesta linha, Bulos (2001), ao se referir sobre as CPI's no período de 1934, frisa que não foi utilizado em toda sua plenitude o valor do novo instrumento de vigilância e controle.

Para finalizar a abordagem acerca da Constituição de 1934, apresenta-se também, como inovador, o caráter representativo das categorias profissionais. O art. 23 estabelecia a possibilidade de serem eleitos representantes de organizações profissionais na forma que a lei indicar. Neste sentido, não se pode deixar de levar em consideração que a representação de caráter profissional acabava por dar uma expectativa de especialização no processo legislativo, mesmo que, eventualmente, o processo de legiferação acabasse sendo delineado por uma proeminente linha corporativista alinhada pelo contexto do Estado Novo.

A Constituição Polaca de 1937 menciona em apenas no artigo 45 as comissões parlamentares, sendo que o período é marcado pela autoridade do Poder Executivo e a concreta cristalização do corporativismo autoritário e legiferante. Transcreve-se:

Art 45 - Qualquer das duas Câmaras ou alguma das suas Comissões pode
convocar Ministro de Estado para prestar esclarecimentos sobre matérias
sujeitas à sua deliberação. O Ministro, independentemente de qualquer
convocação, pode é pedir a uma das Câmaras do Parlamento, ou a qualquer
de suas Comissões, dia e hora para ser ouvido sobre questões sujeitas à
deliberação do Poder Legislativo.

Avançando no tempo, para a Constituição de 1946, apresenta-se o primeiro período efetivamente democrático, sob os ditames de um Estado de Direito, onde vigorava o império da lei. Esse texto constitucional resgatou o prestígio das instituições parlamentares restabelecendo as CPI's e dando de maneira inédita a oportunidade de iniciativa legislativa para as Comissões. 
Redige-se o indigitado artigo:

Art 67 - A iniciativa das leis, ressalvados os casos de competência exclusiva, cabe ao Presidente da República e a qualquer membro ou Comissão da Câmara dos Deputados e do Senado Federal.

Ao tratar do pensamento constitucional brasileiro, Ferreira Filho (1978) lembra que o retrato inicial da Constituição de 1946 foi gradativamente alterado pelo golpe de Estado que se iniciou em 1964. Sendo que, no que diz respeito aos poderes legislativos das comissões parlamentares, houve a relevante emenda de $\mathrm{n}^{\circ} 17$, em 1965, que atribuiu capacidade legislativa plena às comissões, instituindo assim as comissões deliberantes.

O primeiro sistema de comissões deliberantes é proveniente da Constituição italiana de 1947 e tinha como objetivo permitir a produção de normas jurídicas adequadas às novas tarefas de Estado social de direito de forma célere e eficiente. Casseb (2008) menciona que, no caso brasileiro, tal sistema se deturpou, sendo que as comissões despontaram como mecanismos que davam entrada para reinvindicações de setores do próprio governo, não servindo, portanto, para o mote democrático, representativo e pluralista.

Neste caso, é fundamental abordar o ato decorrente do exercício da capacidade legislativa plena das comissões deliberantes, o parecer conclusivo.

Antes da Constituição Federal de 1988, a lei decorrente de parecer conclusivo das comissões deliberantes era denominado lei delegada, haja vista que cabia a casa legislativa "delegar" a capacidade legislativa do seu plenário para as comissões e regulamentar isto por meio do regimento interno, sendo considerada, portanto, uma delegação interna corporis.

A Constituição Federal - CF - de 1988 trouxe no capítulo I - Do Poder Legislativo, Seção VII - Das Comissões, o art. 58 §2 $2^{\circ}$, que prevê a delegação às comissões da apreciação conclusiva sobre projetos de lei, salvo recurso de um décimo dos membros da Casa.

A Constituição Federal de 1988 assegura a representação proporcional dos partidos ou blocos que compõem a casa no plenário das comissões permanentes, não das correntes de opiniões como na constituinte de 1934, ponto importante, tendo em vista que preserva o princípio democrático e pluralista, além de frisar o aspecto partidário da democracia brasileira.

Ademais, verifica-se no arcabouço institucional de 1988 uma efetiva e concreta generosidade no que diz respeito à atuação das comissões parlamentares, sendo a Constituição mais detalhista e atenta com os trabalhos e atribuições desses órgão legislativos, sendo aberta uma seção especifica para regular o tema.

Não obstante, Gomes (2013) ressalta que apesar da Constituinte de 1988 ter fortalecido a produção quantitativa das comissões por meio da apreciação conclusiva das proposições, é provável que as propostas mais relevantes estejam sendo tratadas em Plenário.

Esta breve abordagem histórica sobre os sistemas de comissões serviu para ampliar o panorama de análise e considerar aspectos institucionais ao longo do tempo. Não se pretende 
aqui esgotar o tema ou até mesmo elaborar um tratado histórico sobre as comissões, mas sim, contextualizar o desenvolvimento do objeto de estudo no tempo histórico e social que o permeou.

\section{Tipos de comissões}

As comissões legislativas no Brasil são constituídas na forma e com as atribuições que o regimento interno da respectiva Casa Legislativa lhe atribuir, sempre com observância da representação proporcional dos partidos ou blocos parlamentares.

Neste sentido, o Congresso Nacional possui três tipos básicos de comissões parlamentares: i) permanentes que subsistem através das legislaturas; ii) temporárias que podem ser constituídas para elaboração de estudo sobre um tema individualizado e específico; ii) mistas que são formadas por deputados e senadores.

As comissões permanentes são também chamadas de temáticas e consistem em órgãos especializados que integram a estrutura institucional da Casa Legislativa, tendo a finalidade técnico-legislativa de discutir e votar projetos de lei, realizar audiências públicas, receber petições e reclamações de qualquer pessoa, solicitar depoimentos, bem como convocar ministros para que sejam prestadas informações relacionadas às suas atribuições. É importante ressaltar que o conceito definidor das comissões permanentes está no art. 22, I do Regimento Interno da Câmara dos Deputados:

Art. 22. As Comissões da Câmara são:

I - Permanentes, as de caráter técnico-legislativo ou especializado integrantes da estrutura institucional da Casa, copartícipes e agentes do processo legiferante, que têm por finalidade apreciar os assuntos ou proposições submetidos ao seu exame e sobre eles deliberar, assim como exercer o acompanhamento dos planos e programas governamentais e a fiscalização orçamentária da União, no âmbito dos respectivos campos temáticos e áreas de atuação;

Os nomes das comissões permanentes já indicam o campo de atuação das respectivas matérias que lhes são competentes analisar e estão previstas no artigo 32 do Regimento Interno da Câmara e nos artigos 97 a 104 do Regimento Interno do Senado Federal.

No que diz respeito às comissões temporárias, pode-se dizer que são criadas para fins específicos e se extinguem junto com a legislatura, ou até mesmo antes do seu término se o objetivo pelo qual a comissão foi criada cessar.

Tais tipos de Comissões são definidas pelo Regimento Interno da Câmara dos Deputados também no artigo 22, porém no inciso II, e podem ser de três espécies: Comissões Parlamentares de Inquérito; Comissões Especiais; e Comissões Externas:

II - Temporárias, as criadas para apreciar determinado assunto, que se extinguem ao término da legislatura, ou antes dele, quando alcançado o fim a que se destinam ou expirado seu prazo de duração. 
Diversos autores relatam que as CPI's tem sua origem com o Estado moderno, tendo surgido na Inglaterra, ao final do século XIV (FERREIRA FILHO, 2012; SILVA, 2007; SANDOVAL, 2001).

No Brasil, conforme dito acima, a primeira Constituição que previu as CPI's foi a de 1934, no seu art. 36. A CF de 1988 ampliou, sobremaneira, os poderes anteriormente conferidos às CPI's elegendo apenas três requisitos necessários à instauração do procedimento: i) requerimento assinado por um terço dos membros da Câmara dos Deputados ou do Senado Federal; ii) fato determinado como objeto da investigação parlamentar; iii) e, por fim, prazo certo de duração. Verifica-se, portanto, que as CPI's têm o condão de reunir dados e informações para o exercício das funções constitucionais de controle e investigação do Parlamento.

As Comissões Externas, por sua vez, são comissões temporárias constituídas para atuar fora do âmbito do Congresso Nacional, representando a Casa Legislativa em atos que tenha sido convocada ou a que tenha de assistir. O art. 38 do Regimento Interno da Câmara dos Deputados autoriza a criação de Comissões Externas por ato do Presidente da Câmara, de ofício ou a requerimento de qualquer deputado. Entretanto, se a criação de Comissão trouxer ônus para a Casa, deverá haver deliberação do Plenário.

Ao final, existem as Comissões Especiais, que possuem caráter temporário e são criadas para dar parecer sobre determinadas espécies de proposições, tais como emendas à Constituição, projetos de Código, proposições que versem sobre matéria de mérito de mais de três comissões, previstas no art. 34 do Regimento Interno da Câmara dos Deputados e no art. 74 e seguintes do Regimento Interno do Senado Federal.

Além das comissões anteriormente mencionadas, existem, também, Comissões Mistas, formadas por deputados e senadores, e que podem ser temporárias ou permanentes. A Comissão Mista permanente mais importante do Congresso Nacional é aquela chamada "Comissão Mista do Orçamento", que tem suas atribuições previstas no art. 166 da Constituição Federal de 1988, cabendo-lhe analisar e emitir parecer sobre a lei plurianual do orçamento; as contas apresentadas pelo Presidente da República; exercer o acompanhamento e fiscalização orçamentária, dentre outras. Nas palavras do texto legal:

Art. 166. Os projetos de lei relativos ao plano plurianual, às diretrizes
orçamentárias, ao orçamento anual e aos créditos adicionais serão apreciados
pelas duas Casas do Congresso Nacional, na forma do regimento comum.
$\S 1^{\circ}$ - Caberá a uma Comissão mista permanente de Senadores e Deputados:
I - examinar e emitir parecer sobre os projetos referidos neste artigo e sobre
as contas apresentadas anualmente pelo Presidente da República;
II - examinar e emitir parecer sobre os planos e programas nacionais,
regionais e setoriais previstos nesta Constituição e exercer o
acompanhamento e a fiscalização orçamentária, sem prejuízo da atuação das
demais comissões do Congresso Nacional e de suas Casas, criadas de acordo
com o art. 58 . 
Por fim, ao contrário dos sistemas tradicionais de comissões parlamentares, no Brasil, assim como na Espanha e na Itália, existem comissões deliberativas, termo largamente utilizado para se referir a Competência Legislativa Plena das Comissões (SILVA, 2007; LIMONGI; FIGUEIREDO, 1999; SANTOS, 2000; MULLER; MEIRELES, 2014; GOMES, 2013).

O primeiro sistema de comissões deliberantes é de origem italiana, previsto na Constituição de 1947, e tinha por objetivo permitir a produção de normas jurídicas adequadas às novas tarefas de Estado Social de Direito de forma célere e eficiente.

Nos trabalhos da Assembleia Constituinte italiana, questionou-se o mister de adotar uma fórmula que pudesse responder à exigência, desejada por todos os setores políticos e de parte da opinião pública, de uma legislação rápida e em consonância com as novas tarefas do Estado Social de Direito. Após analisar uma proposta de enviar às comissões projetos sobre leis de caráter mais técnico para que sobre eles se manifestassem em parecer a ser votado pelo plenário sem debates, somente com as declarações de voto, chegou-se ao fim dos trabalhos, em um texto que deferia às comissões não só o exame preliminar dos textos legislativos, mas também a possibilidade de sua provação ou rejeição sem a necessidade de apreciação pelo pleno, salvo em caso de recurso subscrito pelo governo ou pelas minorias. Estabeleceu-se, assim, a ideia de comissioni in sede deliberante (poder conclusivo) (CARNEIRO, 2009).

A Constituição espanhola de 1978, claramente influenciada pela Constituição italiana de 1945, tem consagrada no seu art. 75, 2, a modalidade de comissões deliberantes, também conhecidas como comissões com capacidade legislativa plena, ao estatuir que as Casas Legislativas possuem faculdade de delegação da aprovação dos projetos e propostas de lei ${ }^{2}$ às comissões permanentes.

Conde (apud CASSEB, 2008) assevera que, na Espanha, a opção pelo procedimento de comissões deliberantes ainda não atingiu seu grau máximo de utilização, diferentemente do que acontece em outros países, que empregam com extrema frequência a delegação legislativa para as comissões.

A questão que fica é que apesar do assunto estar na agenda de pesquisa da Ciência Política e do Direito, não se tem notícia de trabalho ou pesquisa acadêmica que tenha abordado de forma comparativa e empírica o grau de institucionalização e efetividade das comissões no Brasil, Espanha e Itália.

\section{Funcionamento e características}

As comissões parlamentares no Brasil receberam especial atenção na Constituição de 1988, sendo que foram idealizadas como um fórum privilegiado de interação entre a sociedade e a Assembleia, funcionando como espaço adequado para audiências públicas, bem como para a

\footnotetext{
${ }^{2}$ Tecnicamente os espanhóis denominam o ato que concretiza a iniciativa legislativa do governo de projeto de lei, ao passo que os atos que consubstanciam a iniciativa dos outros legitimados recebem o nome de proposta de lei.
} 
apresentação de petições, reclamações e queixas, além da extraordinária importância de seu papel fiscalizador (PAES, 2007).

No que diz respeito ao funcionamento e características das Comissões Parlamentares no Brasil, selecionou-se alguns pontos relevantes, levando em consideração o objetivo aqui proposto, bem como ressaltando que o foco do presente estudo é as Comissões Permanentes da Câmara dos Deputados devido à maior produção da literatura e pesquisas sobre o tema, além da possibilidade de futura comparação com outros países.

Assim sendo, elencam-se algumas características do funcionamento das comissões brasileiras : i) locus de representação; ii) controle político; iii) função deliberante;

$\mathrm{O}$ aspecto representativo das comissões se destaca já pela sua previsão constitucional. O art. 58 da CF determina que seja assegurada a representação proporcional dos partidos ou blocos que compõem a casa no plenário das Comissões Permanentes, ponto importante tendo em vista que preserva o princípio democrático e pluralista. Neste diapasão, o Regimento Interno da Câmara dos Deputados, revela, ainda, no seu art. 23, reiterando a necessidade de ampla representatividade, nestes termos:

Art. 23. Na constituição das Comissões assegurar-se-á, tanto quanto possível, a representação proporcional dos Partidos e dos Blocos Parlamentares que participem da Casa, incluindo-se sempre um membro da Minoria, ainda que pela proporcionalidade não lhe caiba lugar. (RICD)

Verifica-se, ainda, que a intenção do Regimento de assegurar a presença inclusiva das minorias, do ponto de vista formal é louvável. Porém há de se destacar que a presença de um, e apenas um membro da minoria torna-se apenas figurativa, já que o sistema de deliberação interno das comissões é majoritário.

A função de representatividade pode também ser traduzida pela participação direta que setores da sociedade exercem nos trabalhos das Comissões por meio de audiências públicas e reuniões abertas, ou seja, é relevante acentuar que o elevado acesso de setores organizados da sociedade aos seus membros acaba por ampliar a sensibilidade destes a uma grande gama de interesses sociais.

Caggiano (2004) ressalta, também, a função de controle do Parlamento, que no caso das comissões parlamentares podem ser traduzidas pela possibilidade institucional que prevê o art. 50 da $\mathrm{CF}$, in verbis:

Art. 50. A Câmara dos Deputados e o Senado Federal, ou qualquer de suas comissões, poderão convocar Ministro de Estado para prestar, pessoalmente, informações sobre assunto previamente determinado, importando crime de responsabilidade a ausência sem justificação adequada.

Percebe-se a vantagem de ampliar não só para a Câmara ou o Senado, mas também para as comissões, a possibilidade de accountability institucional na medida em que amplia-se com isto possibilidades de controle e informação para os setores representativos, reforçando, neste 
sentido, o sistema de freios e contrapesos.

A função deliberante, que consiste na competência legislativa plena das comissões, como já foi ressaltado acima, permite às comissões deliberarem definitivamente sobre algumas proposições legislativas. Assim, a definição de poder conclusivo ou apreciação conclusiva das Comissões Parlamentares está prevista nos arts. 58 e 59 do Regimento Interno da Câmara dos Deputados e pode ser entendida como a faculdade atribuída pela Constituição Federal às comissões do Poder Legislativo para que elas apreciem alguns projetos de lei com poder decisivo, em substituição ao Plenário (CARNEIRO, 2009).

\subsection{Número de Comissões no Congresso}

Neste ponto, serão apresentados os números gerais de todas as comissões pertencentes tanto à Câmara dos Deputados como ao Senado Federal, sem fazer distinção se são permanentes, temporárias ou mistas.

Em 2014 existem 22 (vinte e duas) Comissões Permanentes na Câmara dos Deputados, 17 (dezessete) Comissões Externas em funcionamento, 69 (sessenta e nove) Comissões Especiais, sendo que 33 (trinta e três) delas são comissões formadas para estudar propostas de emenda à Constituição. Além disso, estão em funcionamento 3 (três) CPI's na Câmara.

\begin{tabular}{|l|r|}
\hline CÂMARA & TOTAL \\
\hline Permanentes & 22 \\
\hline Especiais & 69 \\
\hline CPI's & 3 \\
\hline Externas & 17 \\
\hline TOTAL & 111 \\
\hline
\end{tabular}

Quadro 1 - Número total de comissões na câmara dos deputados - 2014

Fonte: Câmara dos Deputados

O Senado Federal, que de uma forma geral conta com números menores, possui 12 (doze) Comissões Permanentes, 9 (nove) Comissões Temporárias, e, por fim, estão em funcionamento 4 (quatro) CPI's.

\begin{tabular}{|l|r|}
\hline SENADO & TOTAL \\
\hline Permanentes & 12 \\
\hline Temporárias & 9 \\
\hline CPI's & 4 \\
\hline TOTAL & 25 \\
\hline
\end{tabular}

Quadro 2 - Número total de comissões no senado federal - 2014

Fonte: Senado Federal

No que concerne às Comissões Mistas, estão em funcionamento apenas 3 (três), que não pertencem nem ao Senado nem à Câmara, mas como explicado anteriormente, são compostas 
por deputados e senadores, fazendo parte, portanto, do Congresso Nacional.

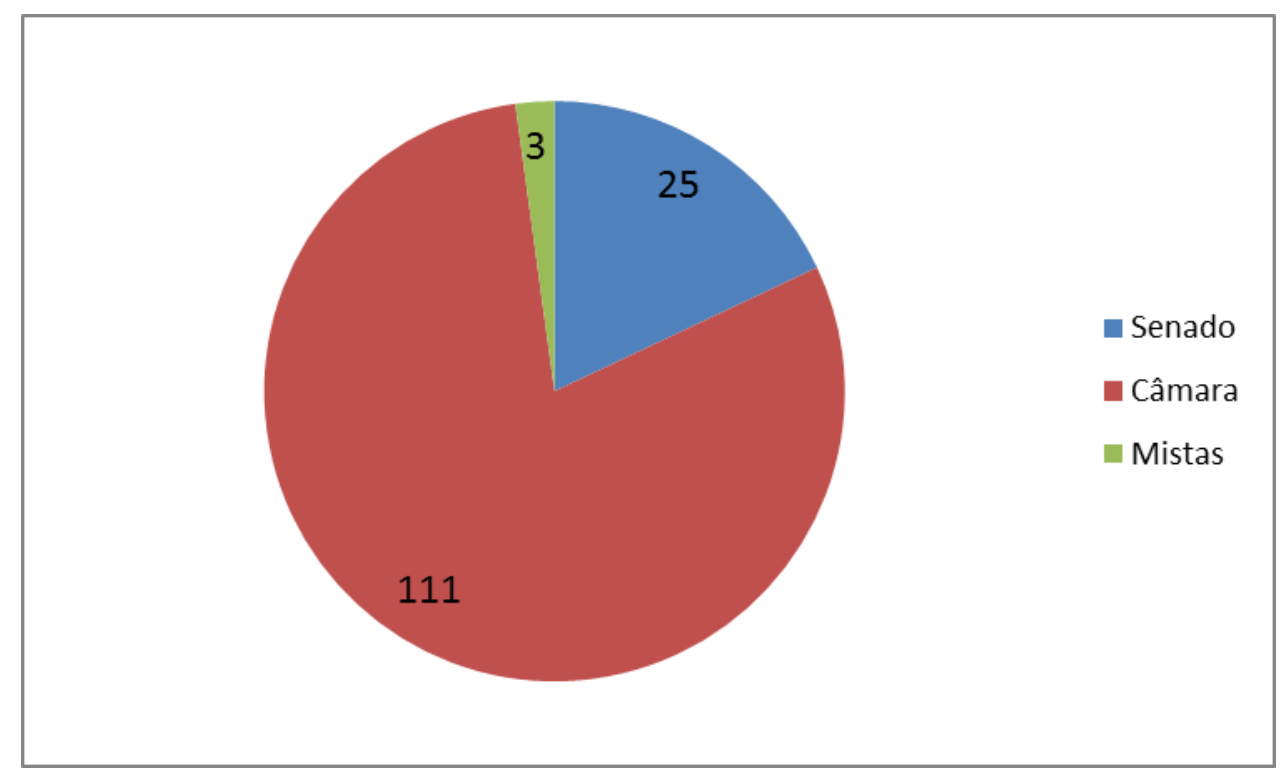

Gráfico 1 - Total de comissões no congresso nacional - 2014

Fonte: Câmara dos Deputados e do Senado Federal

Diante do gráfico acima, conclui-se que atualmente o Brasil possui 139 (cento e trinta e nove) comissões parlamentares em funcionamento no Congresso Nacional, ressaltando-se que neste número estão todos os tipos de comissões parlamentares no âmbito legislativo federal, isto é, as Comissões Permanentes, Temporárias e Mistas.

\subsection{Número de Parlamentares por Comissão}

Um ponto importante é o número de integrantes que cada comissão deve possuir. No caso do Senado Federal, existe a previsão no art. 77 do seu Regimento Interno, da quantidade de membros de cada comissão:

Art. 77. A Comissão Diretora é constituída dos titulares da Mesa, tendo as demais comissões permanentes o seguinte número de membros:

I - Comissão de Assuntos Econômicos, 27;

II - Comissão de Assuntos Sociais, 21;

III - Comissão de Constituição, Justiça e Cidadania, 23;

IV - Comissão de Educação, Cultura e Esporte 27;

V - Comissão de Meio Ambiente, Defesa do Consumidor e Fiscalização e Controle 17;

VI - Comissão de Direitos Humanos e Legislação Participativa, 19;

VII - Comissão de Relações Exteriores e Defesa Nacional, 19;

VIII - Comissão de Serviços de Infraestrutura, 23;

IX - Comissão de Desenvolvimento Regional e Turismo, 17;

X - Comissão de Agricultura e Reforma Agrária, 17.

XI - Comissão de Ciência, Tecnologia, Inovação, Comunicação e Informática - CCT, 17.

As comissões da Câmara dos Deputados, por seu turno, tem previsto no seu Regimento 
Interno, art. $22, \S 2^{\circ}$ o número máximo e mínimo de integrantes de cada comissão através de fração, sendo que o mínimo é três e meio centésimos do total de deputados, que atualmente são 513, sendo este mínimo de 17 deputados. O máximo, por sua vez, é doze centésimos do total, que consiste em 61 deputados federais por comissão.

\subsection{Quantidade de Comissões ao Longo do Tempo}

Outro ponto importante é a variação do número de comissões ao logo do tempo. Para medir esta variável, a fim de simplificar o recurso empírico, limitou-se a mensurar. Apenas, a variação das Comissões Permanentes no Senado Federal e na Câmara dos Deputados após a Constituinte de 1987 até os dias atuais.

Os dados concernentes à Câmara dos Deputados demonstraram relativamente lineares ao longo do tempo, esboçando, assim, grosso modo, uma linha crescente, positiva e linear.

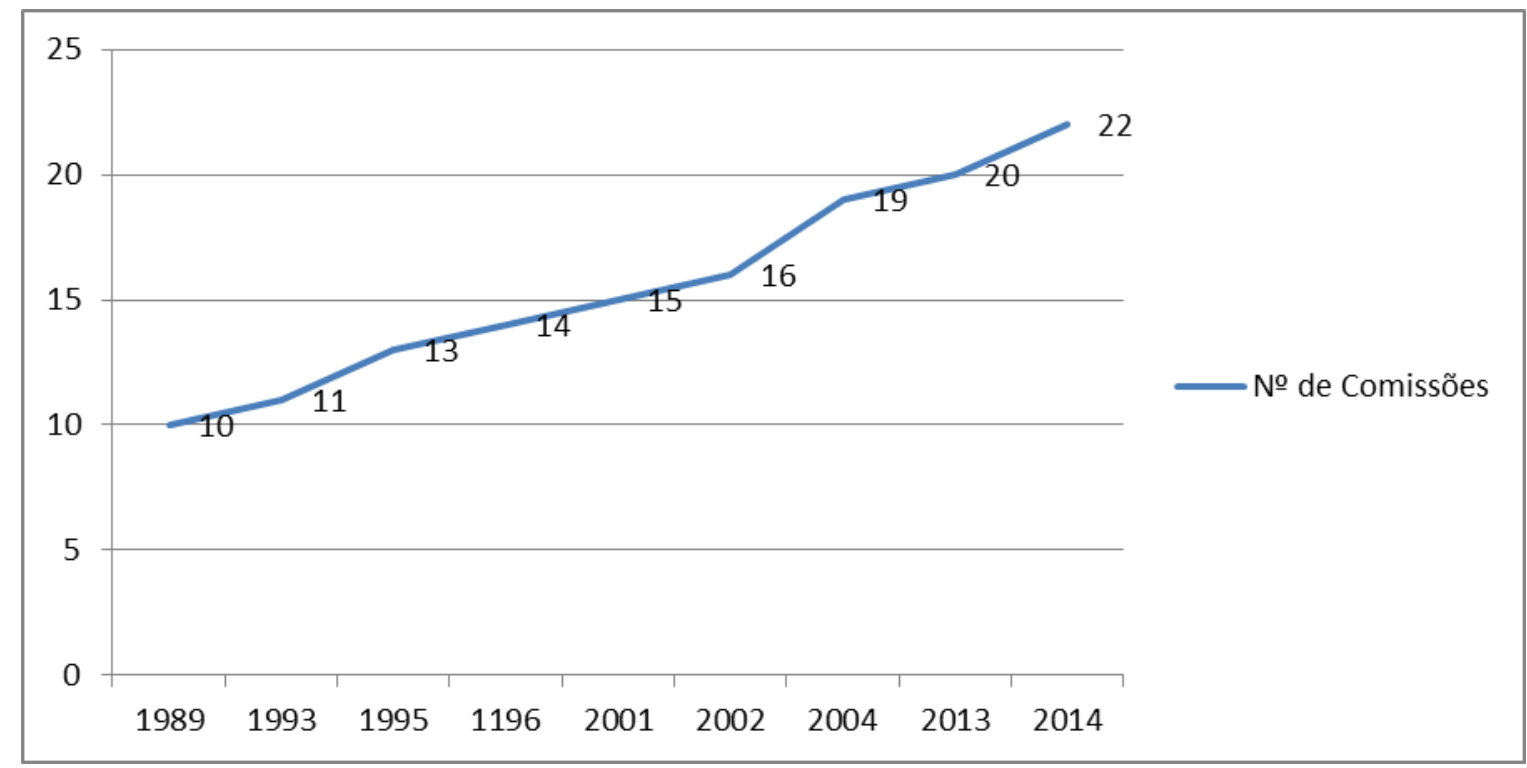

Gráfico 2 - Número de comissões permanentes na câmara dos deputados 1989 - 2014

Fonte: Câmara dos Deputados

Este dado reforça a ideia de que o sistema de Comissões Permanentes vem ganhando uma importância ampliada, dado que o processo legislativo passou ter crescente necessidade de especialização do trabalho na atualidade (MULLER, 2005).

Não procederá a análise da variação das Comissões no Senado porque a literatura tem reconhecido que ao tratar das instâncias de decisão no Legislativo brasileiro existem duas conclusões: i) que a Câmara dos Deputados tem recebido maior atenção que o Senado Federal, provavelmente por ser a Casa Legislativa onde as proposições do Executivo iniciam a tramitação ${ }^{3}$; ii) que os plenários das casas legislativas recebem mais atenção que as Comissões

\footnotetext{
${ }^{3}$ Art. $64, \mathrm{CF} / 88$
} 
(locais em que os trabalhos recebem maior influência dos parlamentares) (GOMES, 2013).

\section{Forma de recrutamento}

Com foco na análise da legislação proposta pelo Executivo no período 1988-2006, um Executivo forte, como o brasileiro, não exclui a possibilidade de que se conforme um sistema de comissões atuante (SANTOS; MEDEIROS; MEDEIROS, 2008).

Assim, boa parte da literatura acaba por associar a descentralização legislativa a uma maior participação dos parlamentares no processo deliberativo e decisório da instituição. Logo, desde o trabalho clássico de Mayhew (1974) onde emerge a linha de raciocínio na qual o fortalecimento do sistema de comissões teria tanto a capacidade de incentivar a aquisição de especialização em alguns temas, como a de fomentar a participação mais efetiva dos parlamentares em decisões. Grande parte dos estudos passaram a trabalhar com a noção de conflito de interesses entre o peso dos partidos e das comissões.

Neste sentido, vale frisar que o debate sobre Executivo forte e sobre comissões atuantes foi particularmente fecundo nos Estados Unidos, haja vista que os estudos sobre o Congresso norte-americano deram origem a três perspectivas analíticas distintas: distributivista, informacional e partidária. Todas elas têm como premissa o individualismo metodológico, partindo da ideia de que os atores agem buscando maximizar seus interesses e ganhos, em especial os parlamentares que buscam a reeleição.

$\mathrm{O}$ vetor distributivista tem como norte axiológico o interesse individual do parlamentar em sua reeleição. Dada à escassez de recursos, se faz necessária uma cooperação entre os deputados para que haja uma distribuição equânime das possibilidades, que se dá por meio do sistema de comissões para uma maximização dos ganhos, isto é, sempre visando a reeleição. Logo, os parlamentares se distribuem pelas comissões de acordo com interesses eleitorais, sendo que a tendência é o parlamentar ter uma longa carreira no interior de uma comissão e, neste caso, vale a regra da seniority (LIMONGI; FIGUEIREDO, 1999; MULLER, 2005). Nessa linha, o sistema de comissões é entendido como eixo estruturador do processo legislativo porque permite "a ocorrência estável da troca de apoio necessária à aprovação de políticas distributivistas" (LIMONGI, 1998, p. 9). Em suma, o que se tem na linha distributivista é, portanto, a característica de negociação em torno da alocação de benefícios políticos (SOARES 2011).

A linha informacional, por sua vez, enxerga o relevante papel das comissões enquanto grupo de trabalho específico, contrapondo-se ao monopólio da informação produzida no Executivo, por meio dos ministérios (SANTOS, 2002; GOMES, 2013; KREHBIEL, 1991). Segundo Krehbiel (1991) um postulado básico desta linha é a incerteza, haja vista que a decisão dos parlamentares não têm a capacidade de prever o resultado eleitoral real das políticas públicas aprovadas. Por essa razão, a redução das incertezas favorece a todos 
indiscriminadamente, o que torna benéfico tomar decisões com o maior número de informações possíveis.

Outro ponto a ser considerado na teoria informacional é que as decisões devem ser tomadas pela maioria. Portanto, o monopólio de informações, neste caso, não é benéfico, pois os parlamentares que as possuem são incentivados a difundi-las. Assim, as comissões são entendidas como microcosmos do plenário operando sobre uma base informacional plural.

Nesse caso, o principal critério para a escolha dos membros das comissões é a expertise, que consiste basicamente no arcabouço profissional do parlamentar. Segundo Santos e Almeida (2005), a experiência prévia ou a formação acadêmica e profissional evitam que a decisão a ser tomada seja racionalmente ignorante.

No que concerne ao viés partidário, temos a concentração da escolha de parlamentares para integrar as comissões nas mãos dos líderes partidários (SANTOS, 2002). Além disso, para esse autor (2002), “analisar as nomeações para as comissões no Brasil significa estudar a decisão de um agente específico, o líder do partido”.

Nesse caso, apesar de serem bem completos, os modelos informacional e distributivista deixam de lado a influência dos partidos. Cox e McCubbins (1993) ressaltam que as comissões não são uma forma de organização que independe dos partidos. Pelo contrário, são arenas que propiciam a promoção de interesses partidários, sobretudo os interesses do partido majoritário; eles frisam, ainda, que as lideranças partidárias são especialmente efetivas nas comissões, haja vista que buscam a coesão interna do partido e são responsáveis pela agenda. Na linha partidária, portanto, como citado por Muller (2005) tem que "no melhor estilo hobbesiano, a autoridade central exercida por meio das prerrogativas regimentais, possibilita aos líderes o controle das indicações para as comissões e o poder de agenda do processo legislativo".

Santos (2002), ao estudar, especificamente, os partidos e comissões no presidencialismo de coalizão, ressalta que a estratégia do líder do partido ao indicar o membro da comissão consiste em considerar que as preocupações com a lealdade política, juntamente com a necessidade de conhecimentos especializados nas políticas públicas da Comissão temática. No caso brasileiro, vê-se que é possível a coexistência de características das três linhas acima mencionadas, isto porque não são excludentes, pelo contrário, são passíveis de coexistência levando-se em consideração determinadas peculiaridades.

Ao contrário dos sistemas tradicionais, como o americano, onde somente cabem às comissões (funções preparatórias), restando protegida a prerrogativa de decisão do plenário, nos sistemas deliberantes, como o brasileiro, as comissões definem qual texto será convertido em lei, em substituição do Pleno da assembleia, ou seja, há uma transferência de deliberação do plenário para as comissões que possuem competência legislativa plena para discutir o projeto, e deliberar de maneira definitiva, mesmo havendo possibilidade de recurso. São considerados como deliberantes o sistema de comissões do Brasil, Itália e Espanha. 
Em recente artigo publicado por Muller e Meireles (2014), o tema do recrutamento para as comissões foi novamente abordado, visando colaborar para a compreensão do processo legislativo e a sua divisão interna de trabalho. Restou claro para os autores que utilizaram métodos estatísticos complexos e rigorosos a existência de uma relação positiva entre expertise e a chance de ingresso nas Comissões. Logo, para eles, a principal forma de explicar a composição das Comissões no Brasil é a linha informacional, corrente à qual filia-se, sem deixar de lado a influência que os partidos e a distribuição de recursos têm no processo.

Tem-se como posição epistemológica que a mescla das várias formas de recrutamento é inerente ao sistema de comissões brasileiro, devido a própria característica da cultura política do sistema partidário e eleitoral no Brasil. Neste sentido, é evidente que não pode-se deixar de mencionar que a expertise é, portanto, o vetor que mais influência os partidos numa conjuntura de recrutamento. Não obstante, é fato que a partidária e distributivista não pode deixar de ser mencionada como fator que influencia de forma efetiva e multicausal o determinante do recrutamento para as comissões parlamentares.

De toda forma, um dos problemas reais que se coloca na agenda da pesquisa sobre o Legislativo é a investigação dos atores que são relevantes em termos de poder decisório e poder de agenda, assim como, quais os elementos que influenciam estes atores a formularem e estabelecerem estratégias para atingirem seus objetivo.

\section{Conclusão}

O tema das comissões parlamentares pode ser abordado sob vários aspectos e por diversos métodos de análise, desde a análise empírica até a análise institucional. No caso do presente trabalho, foi eleita uma abordagem mais geral e normativa, levando-se em consideração aspectos relacionados ao tipo de comissões, seu funcionamento e características, mecanismos legislativos, forma de recrutamento, número de comissões e membros, dando especial relevo para as comissões permanentes.

$\mathrm{O}$ artigo analisou a quantidade de comissões existente atualmente no Congresso e a variação do número de Comissões Permanentes na Câmara dos Deputados ao longo de 25 (vinte e cinco anos). O crescimento da quantidade de comissões ao longo do tempo, aliado a outros fatores, como o grau de institucionalização na Constituição de 1988, e a quantidade de Comissões presentes atualmente no processo legislativo do Congresso Nacional, revelam que as Comissões cumprem um papel importante no processo legislativo, tanto como espaço de deliberação, como aprimoramento técnico do trabalho legislativo.

Os resultados servem apenas para iniciar um trabalho de mensuração sobre o tema, auxiliando como estágio inicial de conhecimento para daí proceder a comparações, principalmente com países como Espanha e Itália, haja vista o sistema de comissões deliberantes existirem nestes países. Não obstante, é fato que diante dos dados assinalados 
podemos deduzir algumas questões, que neste estágio inicial ainda permaneceram sem respostas:

i) Ao longo do tempo, verificamos um aumento do número de Comissões Permanentes na Câmara dos Deputados, sendo que entre os anos de 1989 e 2014 o número mais que dobrou. Neste caso, resta a pergunta: O sistema de comissões estaria servindo de locus para acomodação de forças políticas com o fim exclusivo de obter apoio parlamentar? Ou este número crescente é resultado de demandas do povo decorrente da complexificação social?

ii) Há uma efetiva discrepância entre a quantidade de comissões da Câmara dos Deputados (22) e do Senado Federal (11). A pergunta que se apresenta diante dos dados é: há realmente necessidade de tantas Comissões na Câmara já que o Senado, comumente casa revisora, consegue avaliar os Projetos de Lei com a metade das Comissões?

iii) Verifica-se, também, que existem 69 Comissões Especiais na Câmara dos Deputados. Como foi mencionado, são de criação obrigatória, previstas no art. 34 do Regimento Interno daquela Casa e no art. 74 e seguintes do Regimento Interno do Senado Federal. Pensando em efetividade, eficiência e até mesmo na economia de recursos políticos e materiais a dúvida que resta é: há, efetivamente, a real necessidade de funcionarem tantas Comissões Especiais com a finalidade específica previstas nos diplomas legais supracitados?

\section{Referências}

BRASIL. Câmara dos Deputados. Regimento interno. 13. ed. Brasília: Edições Câmara, 2014. Senado Federal. Regimento interno. Brasília: Senado Federal, 2012.

BULOS, Uadi Lammêgo. Comissão parlamentar de inquérito: técnica e prática. São Paulo: Saraiva, 2001.

CAGGIANO, Monica H. S. Direito parlamentar e Direito Eleitoral. Barueri, SP: Manole, 2004.

CARNEIRO, André Corrêa de Sá. Legislação simbólica e poder de apreciação conclusiva no Congresso Nacional. 2009. 104 f. Dissertação (Mestrado em Ciência Política) - Instituto Universitário de Pesquisas do Rio de Janeiro - Centro de Formação da Câmara dos Deputados, Brasília, 2009.

CASSEB, Paulo A. Processo legislativo: atuação das comissões permanentes e temporárias. São Paulo: RT, 2008.

COX, Gary W.; MCCUBBINS, Mathew D. Legislative leviathan: party government in the house. Berkeley: University California Press, 1993. 
FERREIRA FILHO, Manoel Gonçalves. A constituição de 1967. O pensamento constitucional brasileiro. Diretoria Legislativa da Câmara dos Deputados (coord.). Brasília. Centro de Documentação e Informação da Câmara dos Deputados, 1978.

FERREIRA FILHO, Manoel Gonçalves. Do processo legislativo. 7. ed. São Paulo: Saraiva, 2012.

GOMES, Fabiano de Barros. Produção legislativa no Brasil: visão sistêmica e estratégica no presidencialismo de coalizão. Brasilia: Câmara dos Deputados: 2013.

KREHBIEL, Keith. Information and legislative organization. Michigan: University of Michigan Press, 1991.

LAMOUNIER, Bolivar. A democracia brasileira de 1985 à década de 1990: a síndrome da paralisia hiperativa. In: VELLOSO, João Paulo dos Reis (org). Governabilidade, sistema político e violência urbana. Rio de Janeiro: J. Olympio, 1994.

. Estrutura institucional e governabilidade na década de 1990. In VELLOSO, João Paulo dos Reis. O Brasil e as reformas políticas. Rio de Janeiro: J. Olympio, 1992.

LEITE, Suzana Cristina. Recurso contra o poder conclusivo das comissões: uma análise 2009. Brasília: Câmara dos Deputados, Curso de Especialização em Processo Legislativo, 2009.

LIMONGI, Fernando; FIGUEIREDO, Argelina. Bases institucionais do presidencialismo de coalizão. Lua Nova, 1999. n. 44, p. x-y.

LIMONGI, Fernando; FIGUEIREDO, Argelina. Modelos de legislativo: o legislativo brasileiro em perspectiva comparada. Plenarium, nov. 2004, v. 1, n. 1, p. 40-55.

MAYHEW, David. Congress: the electoral connection. New Haven: Yale University Press, 1974.

MONTERO, Mercedes Garcia; LÓPEZ, Francisco Sanchez. Las comissiones legislativas em América Latina: una classificación institucional y empírica. WP, 2012. n. 212.

MONTESQUIEU. O espírito das leis. São Paulo: Martins Fontes. 2005.

MULLER, Gustavo; MEIRELES, Fernando. O que importa no recrutamento para as comissões permanentes?: partidos, informação e paroquialismo na Câmara dos Deputados (1994 - 2010), IX Encontro da ABCP, Brasília, 2014.

MULLER, Gustavo. Comissões e partidos políticos na Câmara dos Deputados: um estudo sobre os padrões partidários de recrutamento para as comissões permanentes. Dados: Revista de Ciências Sociais, 2005. p. 371-394, v. 48 .

NINA, Carlos Homero Vieira. A comissão parlamentar de inquérito nas Constituições brasileiras. Revista de Informação Legislativa, Brasília, abr./jun. 2005. v. 42, n. 166 .

PAES, Cláudio Ribeiro. Sistema de comissões da Câmara dos Deputados e competência legislativa: análise crítica. Brasília: Câmara dos Deputados, Curso de Especialização em Processo Legislativo, 2007. 
SANDOVAL, Ovídio Rocha Barros. CPI ao pé da letra. Campinas: Millennium, 2001.

SANTOS, Fabiano. Partidos e comissões no presidencialismo de coalizão. Dados: Revista de Ciências Sociais, 2002. p. 237-246, v. 45, n. 2.

SANTOS, Rafael Freitas. MEDEIROS, Danilo Buscato. MEDEIROS, Samuel Moura. Padrões de Atuação das Comissões do Congresso Nacional, 1988-2006. 32 ${ }^{\mathbf{a}}$ Encontro Anual da ANPOCS. Caxambú, 2008.

SILVA, José Afonso. Processo constitucional de formação das leis. 2. ed. São Paulo: Malheiros. 2007.

Artigo recebido em: 05/09/2014

Artigo aceito para publicação em: 12/11/2014 